\title{
PERANCANGAN IDENTITAS KOTA TANJUNGBALAI ASAHAN DENGAN MEMANFAATKAN OBJEK KERANG
}

\author{
Sri Wahyuni Panjaitan ${ }^{1}$ \\ Program Studi Desain Interior, Fakultas Seni dan Desain, Universitas Potensi Utama \\ 1yuniwandriani@gmail.com
}

\begin{abstract}
ABSTRAK
Tulisan ini membahas tentang perancangan Identitas Kota Tanjungbalai Asahan dengan memanfaatkan Objek Kerang. Kota Tanjungbalai Asahan dikenal sebagai kota kerang, karena hasil terbesar dari potensi lautnya adalah kerang. Namun pengenalan Kota Tanjungbalai Asahan belum terolah dan dikemas secara baik. Masih banyak orang yang belum mengetahui Kota Tanjungbalai Asahan sebagai Kota Kerang. Hal tersebut menciptakan image yang kurang menarik bagi masyarakat luas, dan wisatawan. Padahal sesungguhnya Kota Tanjungbalai Asahan mempunyai potensi yang patut dibanggakan oleh Pemerintah dan masyarakatnya. Untuk memperkenalkan Kota Tanjungbalai Asahan secara luas dibutuhkan identitas yang khas dari Kota Tanjungbalai Asahan. Identitas yang dirancang berupa media utama yaitu logo berupa logogram dan media pendukung yaitu gapura selamat datang, gapura Tanjungbalai Food Court, sign system, mug, kaos, x-banner, sticker, kartu nama, name tag, pin, dan gantungan kunci. Semua media tersebut merupakan bagian dari proses Identitas Kota Tanjungbalai Asahan.
\end{abstract}

Kata Kunci : Identitas, Kerang, Logo, Tanjungbalai Asahan

\section{ABSTRACT}

This paper discusses the Design Identity of Tanjungbalai Asahan by using of shell. Tanjungbalai Asahan is known as the city of shells, because the greatest result of its marine potential is shellfish. But the introduction of Tanjungbalai Asahan has not been processed and packaged properly. There are still many people don't know Tanjungbalai Asahan as the City of Shells. It creates an image that is less attractive to many people, and tourists. In fact, Tanjungbalai Asahan has potential to be proud of by the Government and its people. To introduce Tanjungbalai Asahan is widely required a distinctive identity of Tanjungbalai Asahan. Identity that is designed in the form of main media that is logo in the form of logogram and supporting media are welcome gate, gate of Tanjungbalai Food Court, sign system, mug, t-shirt, $x$-banner, sticker, id card, name tage, pin, and key chain. All of these media are part of Identity process of Tanjungbalai Asahan .

Keywords: Identity, Shellfish, Logo, Tanjungbalai Asahan

\section{PENDAHULUAN}

Identitas merupakan salah satu metode yang digunakan untuk dapat dikenali, mengenali, dan membedakan satu hal dengan yang lain. Pada kehidupan, keberadaan identitas sangat diperlukan, tidak hanya manusia yang membutuhkan identitas tapi juga berbagai objek lain disekitar manusia. Manusia hidup tidak hanya berinteraksi dengan sesama manusia saja, tetapi juga berinteraksi dengan makhluk hidup lain maupun benda mati, meskipun pengolahan informasi yang dilakukan bersifat satu arah. Adanya identitas maka manusia bisa membedakan sesuatu (makhluk hidup maupun benda mati) tersebut dengan sesuatu yang lain. 
Tanjungbalai Asahan adalah kota yang berada di provinsi Sumatera Utara. Jarak Kota Tanjungbalai Asahan sekitar $186 \mathrm{~km}$ dan 4 sampai 5 jam dari Medan. Tanjungbalai Asahan berada pada pertemuan dua sungai besar yaitu Sungai Asahan yang merupakan sungai terpanjang di Sumatera Utara dan Sungai Silau yang bermuara ke Selat Malaka. Adanya kondisi tersebut maka Tanjungbalai Asahan mempunyai pelabuhan Teluk Nibung sebagai jalur perdagangan internasioanl dan menjadi tempat lalu lintas barang dan jasa. Perairan Tanjungbalai Asahan memiliki potensi yang sangat besar dari hasil perikanan. Sebagian besar hasil tangkapan adalah kerang, sehingga Tanjungbalai Asahan dijuluki sebagai kota Kerang. Hasil tangkapan kerang diperdagangkan ke luar kota, seperti kota Kisaran, Medan dan kota-kota lainnya, bahkan ke luar provinsi yaitu provinsi Riau yaitu kota Dumai, Bengkalis, Kota Pinang dan Pekan Baru. Oleh karena itu, Pemerintah Daerah terkait membangun podium/panggung berbentuk cangkang kerang raksasa di lapangan Sultan Abdul Jalil atau biasa disebut lapangan pasir. Lapangan Sultan Abdul Jalil adalah alun-alun dan pusat keramaian Kota Tanjungbalai Asahan. Lapangan ini digunakan pada berbagai kegiatan seperti Upacara Bendera Kemerdekaan Indonesia, Festival dan Pesta Kerang, Pasar Malam, Festival MTQ dan kegiatan-kegiatan lain yang bersifat kemasyarakatan. Pesta kerang dan Festival kerang merupakan acara perayaan hari jadi Kota Tanjungbalai Asahan dan penyambutan tahun baru.

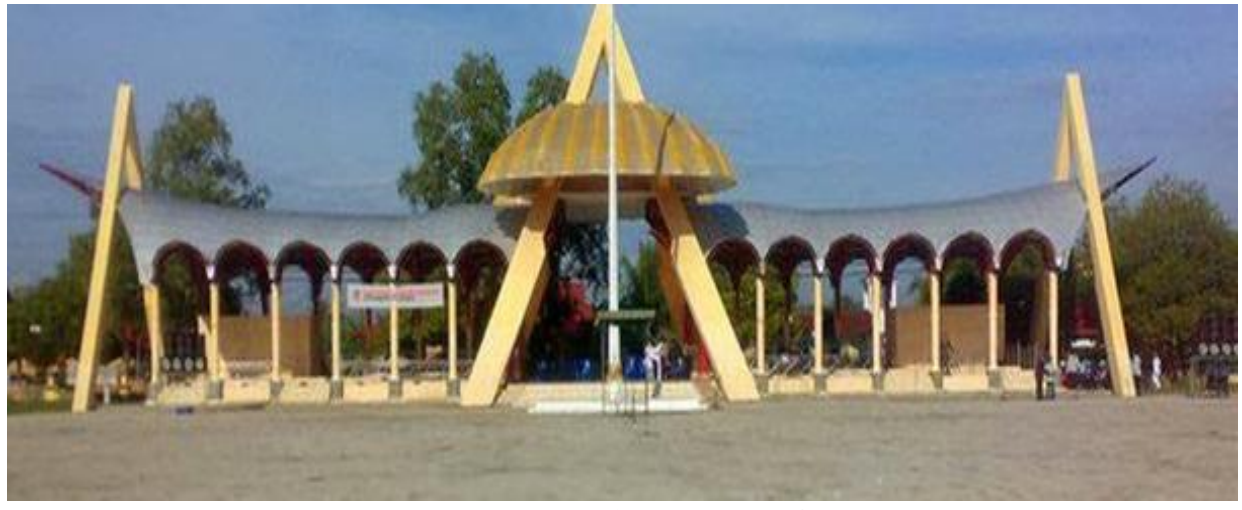

Gambar 1. Lapangan Pasir ( Lapangan Sultan Abdul Jalil

Simbol Tanjungbalai Asahan sebagai kota kerang tidak hanya diimplementasikan pada podium/panggung, kota ini juga memiliki simbol pada lagu daerah yang berjudul Tanjungbalai Si Kota Kerang yang diciptakan oleh Abah Dayat dan juga memiliki kerajinan kerang. Umumnya limbah cangkang kerang terbuang dan sangat sulit untuk musnah. Seiiring perkembangan zaman beberapa masyarakat Tanjungbalai Asahan memiliki ide kreatif untuk memanfaatkan limbah cangkang kerang diolah menjadi berbagai produk bernilai jual. Limbah cangkang kerang diolah menjadi tempat tisu, bunga, baki, dan perlengkapan adat Melayu, Tepak Sirih dan lain-lain. Selain itu yang berkaitan dengan kerang, Tanjungbalai Asahan memiliki wisata kuliner yaitu kerang rebus, rebus kemudi kapal, asam manis kepah, sate kerang, rendang kerang, dan lain-lain yang bisa ditemukan di Tanjungbalai Food Court. Tempat ini berada di belakang podium/panggung cangkang kerang. 


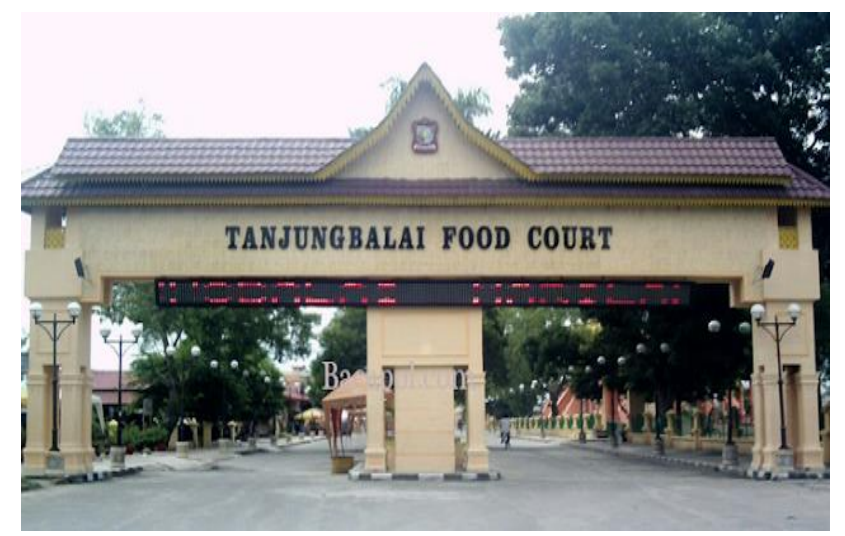

Gambar 2. Tanjungbalai Food Court

Potensi yang dimiliki Kota Tanjungbalai Asahan belum terpublikasi dan masih banyak orang yang belum mengetahui tentang Kota Tanjungbalai Asahan. Kota Tanjungbalai Asahan terhimpit dengan keberadaan Kota Medan sebagai ibu kota provinsi Sumatera Utara. Sehingga yang ada diingatan orang adalah Medan. Selain itu Kota Tanjungbalai Asahan juga terbelakangi dengan Kota Kisaran yang bersebelahan dengan Kota Tanjungbalai Asahan. Kota Kisaran banyak dikenal dan dikunjungi karena memiliki Masjid Haji Ahmad Bakrie dan alun-alun Kota Kisaran. Oleh karena itu, hanya segelintir orang yang mengetahui tentang Tanjungbalai Asahan. Selain itu, Kota Tanjungbalai Asahan belum memiliki brand yang kuat walaupun telah memiliki simbol sebagai Kota Kerang. Menurut Wheeler (2009:2) brand adalah pemberian cap identitas suatu produk ( wilayah dalam perancangan penulis ) untuk pembeda dengan produk yang lain bertujuan agar produk diingat oleh konsumen dan berbeda dengan produk lainnya.

Selain itu Tanjungbalai Asahan telah memiliki Lambang Pemerintahan Kota Tanjungbalai Asahan, namun lambang tersebut sulit untuk memberi positioning yang baik bagi masyarakat, karena bentuk lambang Kota Pemerintahan sulit untuk diingat. Lambang Kota Tanjungbalai Asahan terdiri dari beberapa icon yang sulit untuk diingat dan terdiri dari warna hitam, putih, kuning, biru, hijau, merah, dan coklat. Lambang Kota Tanjungbalai Asahan merupakan lambang kota secara umum, Tanjungbalai Asahan belum memilki Lambang atau Logo secara khusus yang mencirikhaskan Kota Tanjungbalai Asahan sebagai Kota Kerang.

Adanya fenomena tersebut maka penulis merancang sebuah identitas yang mencirikhaskan Kota Tanjungbalai Asahan agar masyarakat mengenal Kota Tanjungbalai Asahan sebagai Kota Kerang yaitu dengan judul "Perancangan Identitas Kota Tanjungbalai Asahan dengan Memanfaatkan Objek Kerang”. Kota Tanjungbalai Asahan memiliki banyak potensi yang masih butuh pengenalan dengan tepat.

Metode penciptaan yang digunakan pada perancnagan identitas Kota Tanjungbalai Asahan adalah sebagai berikut :

1. Metode persiapan yaitu pada tahap ini merupakan tahap persiapan untuk merealisasikan konsep yang telah dibuat pada Perancangan Identitas Kota Tanjungbalai Asahan dengan memanfaatkan Objek Kerang. Pertama untuk tulisan laporan karya yang dilakukan perancang adalah riset ke Dinas Pariwisata, Kebudayaan, dan Pemuda Olahraga. Mengumpulkan data-data yang berkaitan dengan perancangan Identitas Kota Tanjungbalai Asahan. Selanjutnya mengamati atributatribut di Kota Tanjungbalai Asahan yang berkaitan dengan kerang yaitu podium cangkang kerang, lautan, sungai, dan kerang. Kemudian melakukan riset ke salah satu UKM kerajinan kerang yaitu UKM Mutiara Lautan, mencari referensi jurnal, dan 
membaca laporan karya di perpustakaan ISI Padangpanjang untuk perbandingan karya yang dirancang dengan perancangan karya sebelumnya.

2. Metode Eksplorasi yaitu pada tahap ini pengkarya mengeksplore Kota Tanjungbalai Asahan ,karena pengkarya membutuhkan sumber inspirasi, referensi dari berbagai data dan fenomena untuk memperkenalkan Tanjungbalai Asahan secara luas melalui Perancangan Identitas Kota Tanjungbalai Asahan. Pengkarya mengamati Kota Tanjungbalai Asahan untuk proses perancangan Identitas berupa logogram. Proses perancangan identitas pengkarya mengamati beberapa jenis kerang dan keong untuk dijadikan objek pada logogram. Selain itu pengkarya melakukan riset dan wawancara kepada Ibu Hotnida Harahap selaku pengelola UKM Mutiara Lautan dan mengamati semua jenis kerajinan yang telah dibuat. Selanjutnya pengkarya mengamati hal-hal yang berkaitan dengan perancangan seperti mengamati laut, air laut, lingkungan, dan podium/pentas cangkang kerang. Hasil dari mengeksplore Kota Tanjungbalai Asahan dapat dituangkan pada brainstorming.

Menurut Rustan (2010:36) brainstorming adalah kegiatan yang dilakukan untuk mendapatkan solusi, mengeluarkan ide-ide sehingga bisa dikembangkan dengan baik. Intinya sebuah brainstorming adalah mengeluarkan ide-ide sebanyak mungkin, keluar dari pola pikir yang konvensioanal dan menciptakan strategi, ide, dan inspirasi. Berikut adalah brainstorming Tanjungbalai Asahan.

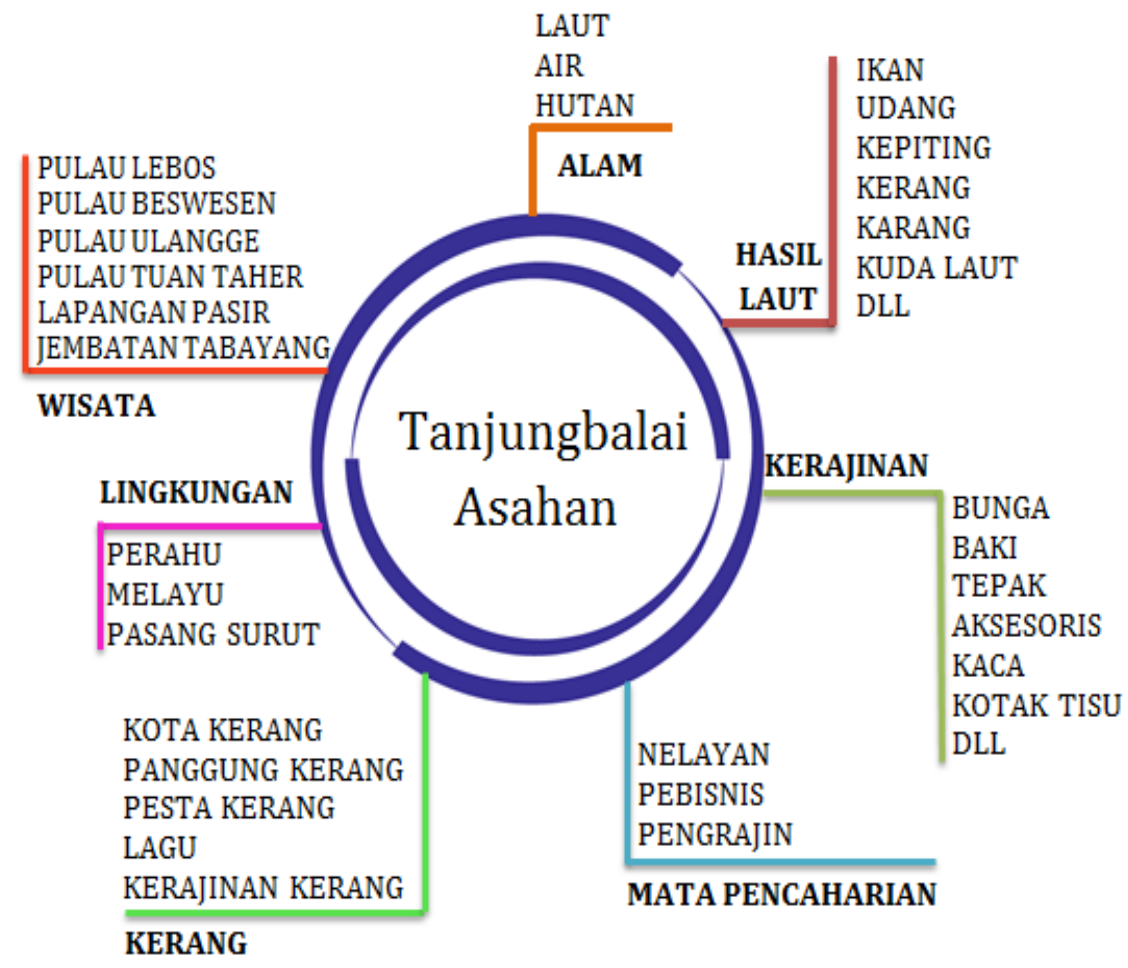

Gambar 3. Brainstorming Tanjungbalai Asahan

\section{STUDI LITERATUR}

Penciptaan sebuah karya memerlukan kajian dari beberapa karya perancangan desain terdahulu yang berhubungan dengan perancangan yang pengkarya lakukan. Selain beberapa karya, pengkarya juga menelaah beberapa karya tulis yang juga berhubungan dengan perancangan yang pengkarya lakukan. Ini bertujuan untuk menjaga orisinalitas karya yang pengkarya rancang. Karya dan tulisan yang berkaitan dengan perancangan Identitas Kota Tanjungbalai Asahan dengan Memanfaatkan Objek Kerang antara lain: 
1. Haris Satria, City Branding Kota Padang, 2013, Program Pascasarjana, Institut Seni Indonesia Padangpanjang.

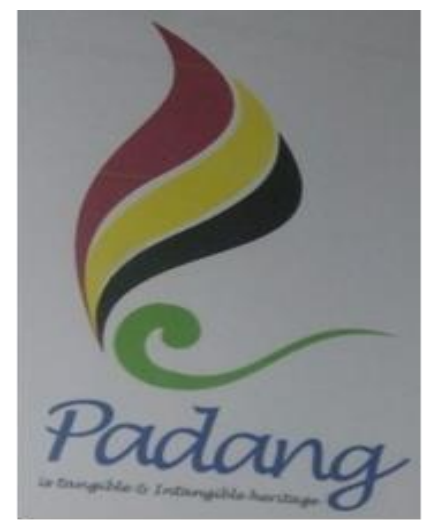

Gambar 4. City Branding Padang

City Branding Padang adalah sebuah proses dan usaha membentuk merek kota Padang yang merupakan kota wisata untuk diperkenalkan kepada masyarakat luas. Konsep perancangan City Branding Kota Padang yang dimunculkan melalui konsep verbal dan konsep visual. Konsep verbal City Branding Kota Padang menggunakan kata-kata yang sederhana namun memberikan kesan bermakna sehingga image yang diharapkan sampai kepada khalayak. Konsep verbal City Branding Kota Padang menggunakan tageline kalimat bahasa Inggris yaitu "Tangible \& Intangible Heritage" yang artinya warisan budaya yang berwujud dan tidak berwujud ( bendawi dan non bendawi ).

Konsep visual yang digunakan diambil dari alam dan lingkungan (kebudayaan). Warna dari alam yaitu warna hijau menggambarkan kelapa dan daun kelapa. Warna tersebut digunakan sebagai elemen dari budaya yang memiliki kesan alami, sehat dan nyaman. Warna dari lingkungan (kebudayaan) yang digunakan adalah warna merah, kuning, dan hitam. Warna merah, kuning dan hitam merupakan gambaran dari marawa yang merupakan identitas orang Minangkabau dan warna ini melambangkan keberanian, semangat dan tahan uji. Unsur tersebut akan digabungkan sehingga memberikan kesan sederhana, menarik dan mudah diingat serta dipahami. Warna-warna tersebut merupakan deskripsi dari Kota Padang secara utuh.

Rancangan City Branding diwujudkan dalam berbagai bentuk media komunikasi yang efektif. Media rancangannya adalah logo beserta aplikasinya seperti billboard, akun facebook, kaos, mug, gantungan kunci, sign area, poster, pin, post card, sticker, kalender, dan flaxchange.

Konsep perancangan yang pengkarya lakukan untuk merancang Identitas Kota Tanjungbalai Asahan dengan Memanfaatkan Objek Kerang adalah menggunakan konsep verbal dan konsep visual. Konsep verbal menggunakan tageline bahasa Indonesia agar mudah diingat dan diucapkan, berbeda dengan konsep perancangan City Branding Padang menggunakan bahasa inggris. Konsep visual yang digunakan pengkarya sama seperti konsep visual City Branding Padang menggunakan warna dari alam dan lingkungan (kebudayaan). Pengkarya menggunakan warna dari alam yaitu warna biru laut, karena daerah ini berada di pesisir laut. Warna yang digunakan yaitu kuning yang merupakan warna kebudayaan Kota Tanjungbalai Asahan sebagai daerah melayu. 
2. Riki Iskandar, Branding Songket Silungkang, 2016, Program Pascasarjana Institut Seni Indonesia Padangpanjang

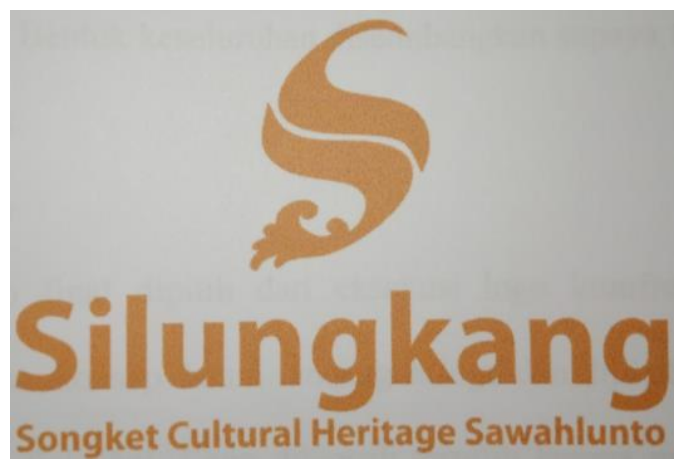

Gambar 5. City Branding Padang

Pada perancangan Branding Songket Silungkang menggunakan konsep dari motif-motif pada kain songket, namun bentuknya disederhanakan. Branding yang dirancang berupa tipografi huruf $\mathrm{S}$ jenis corporate typeface merupakan pembuatan tulisan yang lebih bertujuan untuk menunjukkan kepribadian merek dan konsistensi identitas hingga ke elemen-elemen terkecil atau bisa disebut dengan logotype. Warna yang digunakan hanya satu warna yaitu warna orange.

Konsep Branding Songket Silungkang dan konsep perancangan yang dirancang pengkarya jauh berbeda, perancang merancang identitas Kota Tanjungbalai Asahan berupa logogram (logo berupa gambar), sedangkan Branding Songket logo yang dirancang berupa logotype yaitu logo berupa tulisan. Warna yang digunakan lebih dari satu yaitu warna biru, hijau, silver, dan kuning. Berbeda dengan Branding Songket menggunakan satu warna yaitu orange. Penggunaan beberapa warna pada perancangan Identitas Tanjungbalai Asahan mempunyai makna yaitu Tanjungbalai Asahan memiliki hasil perikanan laut berupa ikan, udang, cumi-cumi, kepiting, keong dan kerang. Namun sebagian besar hasil tangkapan adalah kerang dan banyak jenis kerang yang terdapat di perairan laut Tanjungbalai Asahan. Kondisi tersebut menjadikan Tanjungbalai Asahan sebagai kota kerang. Kata kerang terdapat pada atribut Tanjungbalai Asahan yaitu podium/panggung cangkang kerang, Pesta dan Festival Kerang, kerajinan kerang, kuliner kerang dan lagu daerah Tanjungbalai yang berjudul Tanjungbalai Si Kota Kerang. Persamaan pada perancangan logo Songket dan identitas Tanjungbalai Asahan adalah tageline yang digunakan jenis tipografi letter marks. Jenis tipografi letter marks adalah jenis huruf yang sudah ada.

\section{PEMBAHASAN}

\section{III.I. Rancangan Konsep Garapan}

1. Konsep Umum

Konsep yang digunakan pada perancangan Identitas Kota Tanjungbalai Asahan dengan Memanfaatkan Objek Kerang adalah konsep pendayagunaan kerang. Maksud pendayagunaan kerang adalah dengan adanya kerang dapat menjadi sumber penghasilan bagi nelayan, pebisnis kerang, dan pengrajin kerang. Selain itu kerang dapat diolah menjadi beberapa masakan seperti kerang rebus, sate kerang, rendang kerang dan lain-lain. Cangkang kerangnya dapat dimanfaatkan untuk membuat 
kerajinan seperti bunga, tepak sirih, bunga balai, tempat tisu dan lain-lain. Objek kerang merupakan potensi yang ingin ditonjolkan pada perancangan ini. Kota Tanjungbalai Asahan yang memilki hasil kekayaan laut yang terbesar yaitu kerang menjadikan brand yang dapat memberikan cap identitas Kota Tanjungbalai Asahan sebagai Kota Kerang.

2. Konsep Visual

Perancangan identitas Tanjungbalai Asahan untuk membangun citra merek Kota Tanjungbalai Asahan perancang melakukan beberapa tahapan yaitu membuat logo dan media desain. Identitas Kota Tanjungbalai Asahan yang dirancang yaitu logo berupa logogram. Logo yang dirancang diantaranya adalah unik atau original berbeda dengan yang lain, simple untuk mudah diingat, dan fleksibel agar mudah dalam penggunaan pada media desain.

Menurut Swasty (2016: 124) logo dapat terdiri dari beberapa gambar pada semua atribut non-fisik seperti visi, misi, nilai, kepribadian dan budaya perusahaan. Sedangkan menurut Rustam (2013: 13) logo adalah elemen gambar/simbol pada identitas visual. Logo berfungsi sebagai identitas diri untuk membedakan dengan identitas milik orang lain, sebagai tanda kepemilikan, tanda jaminan kualitas dan mencegah peniruan/pembajakan.

Secara visualisasi, logo adalah suatu gambar. Gambar tersebut bisa berupa berbagai unsur bentuk dan warna. Oleh karena sifat dari apa yang diwakili oleh logo berbeda satu sama lain, maka logo pula memilki bentuk yang berbeda pula. Bentuk logo yang berbeda dapat meliputi bentuk fisik, warna maupun dimensi (Kusrianto 2007: 231233). Logo yang dirancang pada Perancangan Identitas Kota Tanjungbalai Asahan dengan Memanfaatkan Objek Kerang yaitu berupa logogram.

Menurut Swasty (2016: 41) Logogram diartikan sebagai logo yang berupa unsur gambar. Perancangan logogram Kota Tanjungbalai Asahan ditekankan pada karakter dan cirikhas yang dimilki oleh Kota Tanjungbalai Asahan yaitu objek kerang. Tahap selanjutnya perancangan media desain yaitu seperti gapura selamat datang, $\mathrm{x}$ banner, spanduk, pin, mug, kaos, gantungan kunci, aksesoris dan lain sebagainya. Berikut objek kerang yang digunakan untuk merancang identitas Kota Tanjungbalai Asahan. Berikut adalah objek yang digunakan untuk merancang identitas Kota Tanjungbalai Asahan.

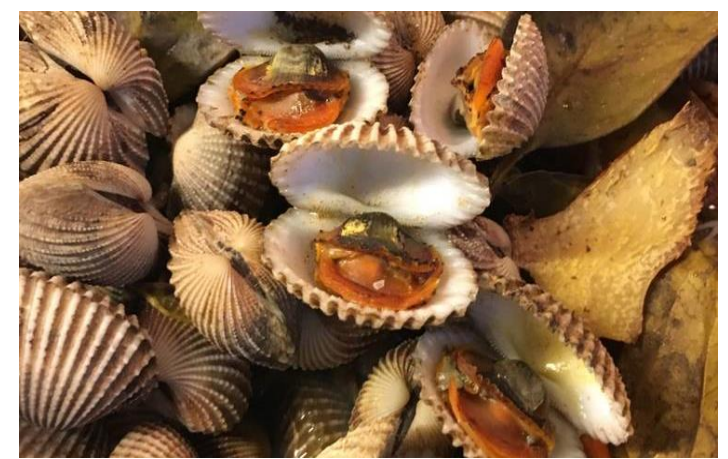

Gambar 6. Kerang Dara

\section{Konsep Warna}

Menurut Sanyono (2010:11) bahwa warna dapat didefenisikan secara objektif/fisik berdasarkan factor cahaya yang dipancarkan dan dapat juga didefenisikan secara subjektif psikologis sebagai bagian dari pengalaman indra penglihatan. Berdasarkan objektif/fisik warna dibagi berdasarkan panjang gelombang yang 
dipancarkan dan diterima oleh mata. Defenisi warna berdasarkan subjektif/psikologi yaitu dapat diartikan berdasarkan makna yang tercipta dari respon psikologi dari masing-masing warna. Biasanya makna-makna ini tercipta berdasarkan pengalaman, sensasi yang dipancarkan, budaya, tren, penglihatan, dan aspek sosial.

Warna merupakan unsur visual yang penting digunakan dalam desain. Pemilihan warna yang tepat merupakan proses yang sangat penting untuk mendapatkan desain yang sesuai dengan harapan. Warna yang digunakan pengkarya pada perancangan identitas Kota Tanjungbalai Asahan menggunakan warna dari alam yaitu biru, hijau, silver dan warna kuning. Warna yang dominan atau lebih banyak digunakan pada perancangan identitas Kota Tanjungbalai Asahan adalah warna kuning, karena warna kuning merupakan warna kebudayaan Kota Tanjungbalai Asahan sebagai daaerah melayu. Kota Tanjungbalai Asahan merupakan daerah peninggalan Kesultanan Abdul Jalil Rahmadsyah sebagai Sultan Asahan I merupakan putra dari Sultan Mahmud Syah yang berasal dari Kabupaten Siak Sri Inderapura.

4. Konsep Verbal

Bentuk verbal yang akan dirancang tentu menggunakan kata yang berhubungan dengan laut. Perancangan identitas Kota Tanjungbalai Asahan mencerminkan hasil laut bertujuan untuk memberikan image Kota Tanjungbalai akan dikenal sebagai kota pesisir. Selain itu konsep verbal yang berhubungan dengan hasil laut dapat menjadi positioning yang kuat dalam benak masyarakat Indonesia. Perancangan brand name pada perancangan identitas Kota Tanjungbalai Asahan menggunakan tageline bahasa Indonesia yang singkat, simple, dan mudah diingat oleh target audient.

5. Konsep Tipografi

Elemen yang tidak kalah penting dari elemen pemilihan warna adalah tipografi. Menurut Rustan (2010 : 10), tipografi menjadi unsur vital dalam efektifitas komunikasi, baik cetak maupun elektronik. Tipografi sendiri merupakan seni dalam mengatur huruf (Kasali, 1995 : 90). Huruf dengan berbagai jenis dan gaya disebut sebagai typeface. Ada dua macam tipografi, yaitu tipografi dalam logo letter marks dan corporate typeface. Pada letter marks, huruf yang digunakan adalah jenis huruf yang sudah ada, sedangkan corporate typeface merupakan pembuatan tulisan yang lebih bertujuan untuk menunjukkan kepribadian merek dan konsistensi identitas hingga ke elemen-elemen terkecil. Pada perancangan Identitas Kota Tanjungbalai Asahan pengkarya menggunakan jenis tipografi letter mark (bagian logo yang berbentuk tulisan) untuk memperkuat logogram yang akan dirancang.

A. Bentuk Karya

1. Alternatif Verbal

- Kota Kerang

- Kota Kerang Sumatera Utara $\checkmark$

- Kerangnya Sumatera Utara

2. Altematif Tipografi

$$
\begin{aligned}
& \text { 1. Logotype } \\
& \text { Tanjungbalai } \\
& \text { Tanjungbalai } \\
& \text { Tanjungbalai }
\end{aligned}
$$

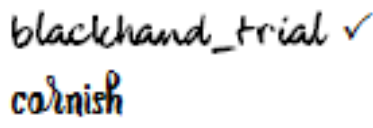

Segoe Print 
2. Tageline

\section{KOTA KERANG SUMATERA UTARA}

Kota Kerang Sumatera Utara

Kota Kerang Sumatera Utara
NEW ATHLETIC M54

NipCen's Print Unicode

Coves

2. Visualisasi Logogram

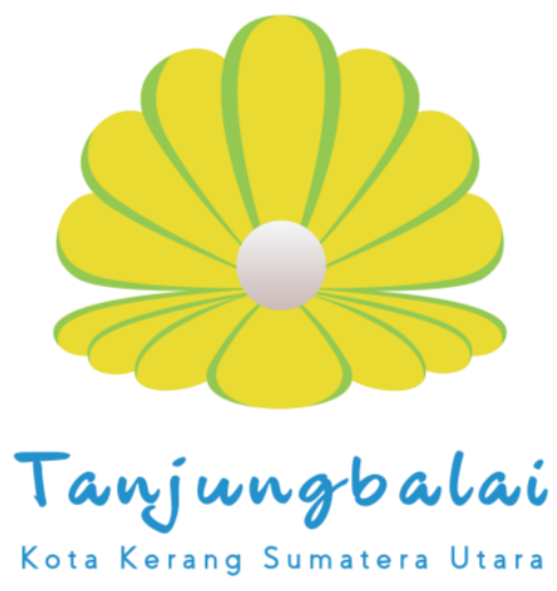

Gambar 7. Final Logo

Deskripsi Logo :

1. Warna kuning merupakan warna kebudayaan Kota Tanjungbalai Asahan yaitu kebudyaan melayu. Selain itu warna kuning memiliki makna salah satunya kehidupan. Artinya kehidupan masyarakat Kota Tanjungbalai Asahan adalah kebudayaan melayu. Kota Tanjungbalai Asahan banyak masyarakat yang memiliki marga beragama islam, namun kehidupannya tetap pada tradisi melayu.

2. Warna Hijau menggambarkan pulau dan tepian sungai, artinya Kota Tanjungbalai Asahan memiliki banyak pulau-pulau kecil yang dikelilingi dengan hutan dan pepohonan dan juga ditepian sungai terdapat hutan dan pepohonan. Selain itu hijau maknanya kesuburan artinya daerah Kota Tanjungbalai Asahan merupakan daerah pesisir yang hasil lautnya terus menerus berkembangbiak.

3. Bentuk bulat ditengah dan warna Silver menggambarkan mutiara yang identik dengan kemewahan atau materi artinya Kota Tanjungbalai Asahan sebagai kota kerang menjadi sumber penghasilan dan dapat meningkatkan perekonomian bagi masyarakat Kota Tanjungbalai Asahan.

4. Warna biru menggambarkan lautan, artinya Kota Tanjungbalai Asahan dikelilingi oleh sungai dan lautan. Selain itu makna biru adalah kesatuan, artinya para nelayan saling bekerja sama untuk mendapatkan hasil laut sebagai mata pencaharian mereka.

5. Bentuk logogram merupakan stilasi dari cangkang kerang dara yang terbuka. Penggunaan objek cangkang kerang dara terinspirasi dari podium/pentas Lapangan Sultan Abdul Jalil dan cangkang kerang yang banyak digunakan untuk membuat kerajinan. Cangkang kerang dara merupakan cangkang kerang yang kuat dan keras dibandingkan dengan 
cangkang kerang lainnya. Maksudnya para nelayan harus kuat dan bekerja keras untuk mendapatkan hasil laut.

6. Jenis tipografi pada logotype seperti ilustrasi air, artinya Kota Tanjungbalai Asahan adalah kota berada pada pesisir laut.

7. Tageline kota kerang sumatera utara menjelaskan bahwa Kota Tanjungbalai Asahan merupakan kota kerang yang berada di Sumatera Utara.

3. Pengaplikasian Logo

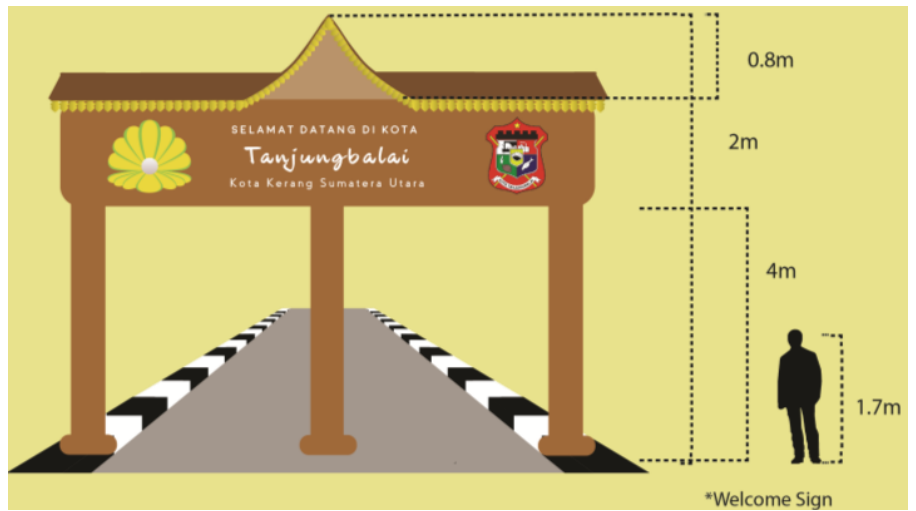

Gambar 8. Desain Gerbang Tanjungbalai Food Court

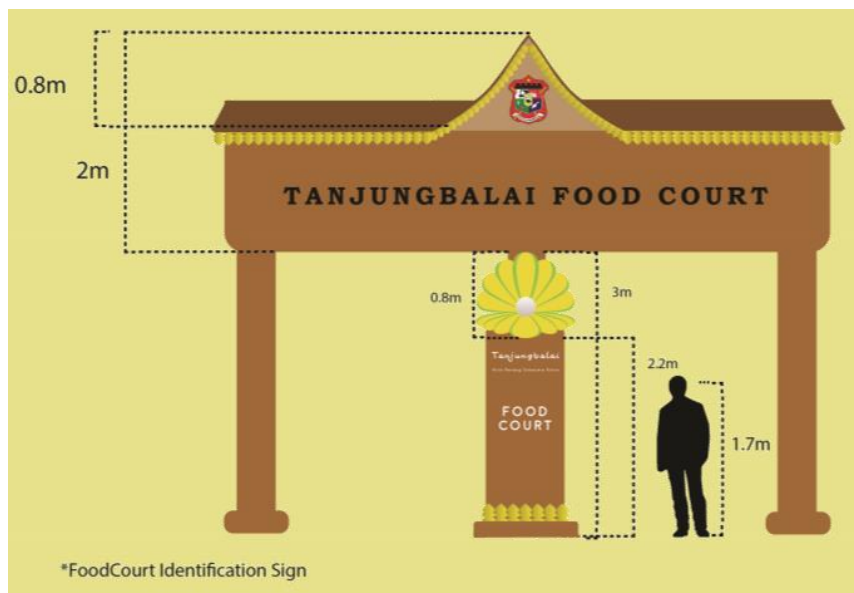

Gambar 9. Desain Gerbang Tanjungbalai Food Court

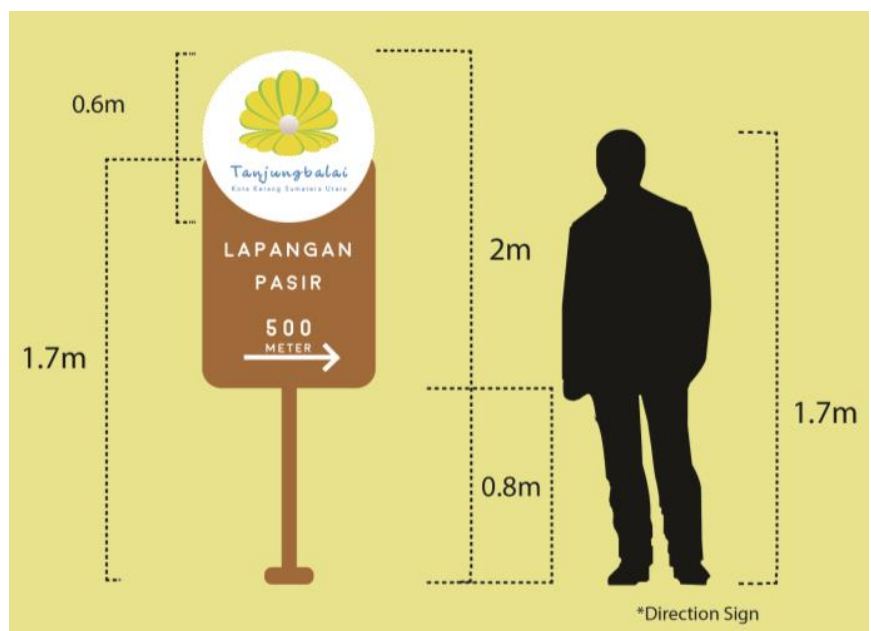

Gambar 10. Desain Sign System 

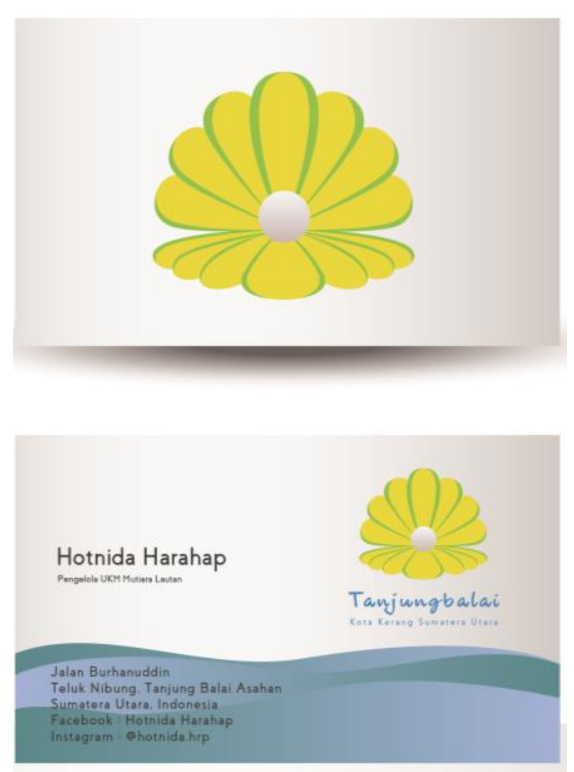

Gambar 11. Desain Kartu Nama

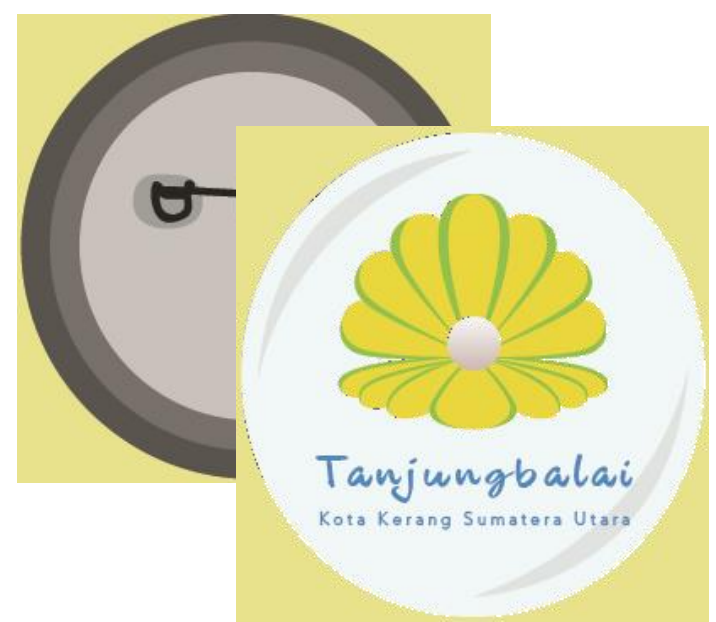

Gambar 13. Desain Pin

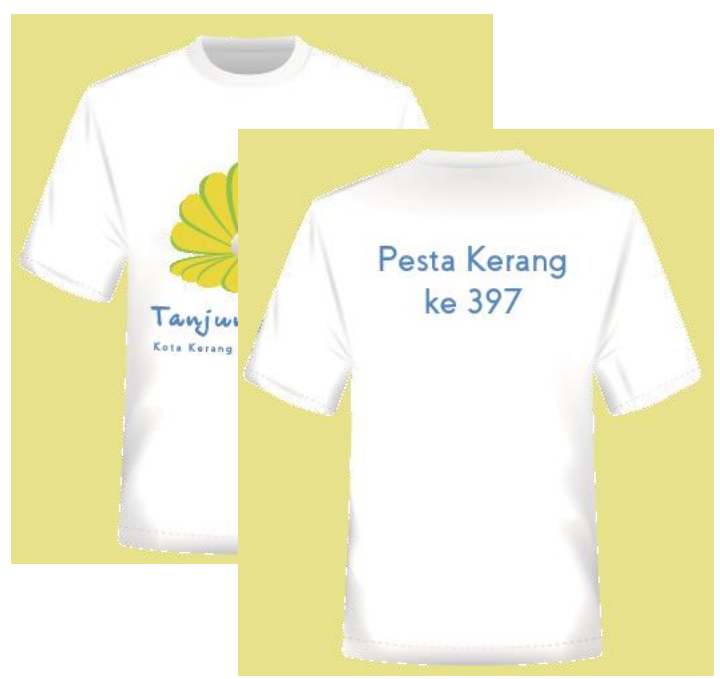

Gambar 15. Desain Mug

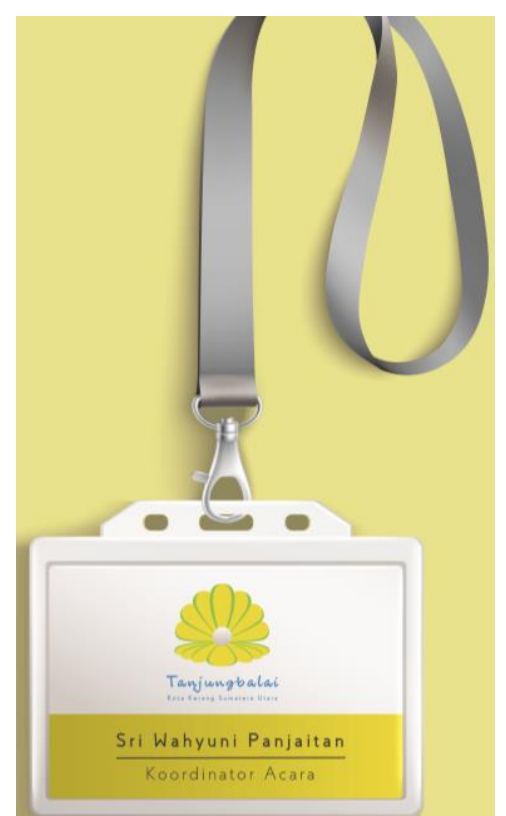

Gambar 12. Desain Name Tage

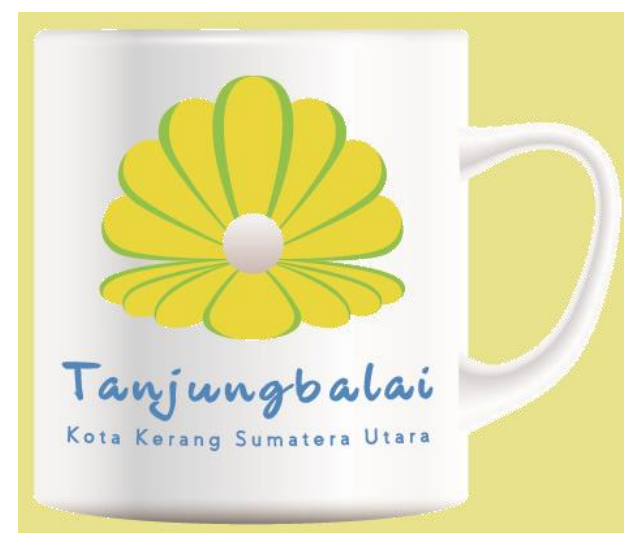

Gambar 14. Desain Mug

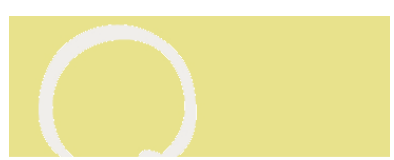




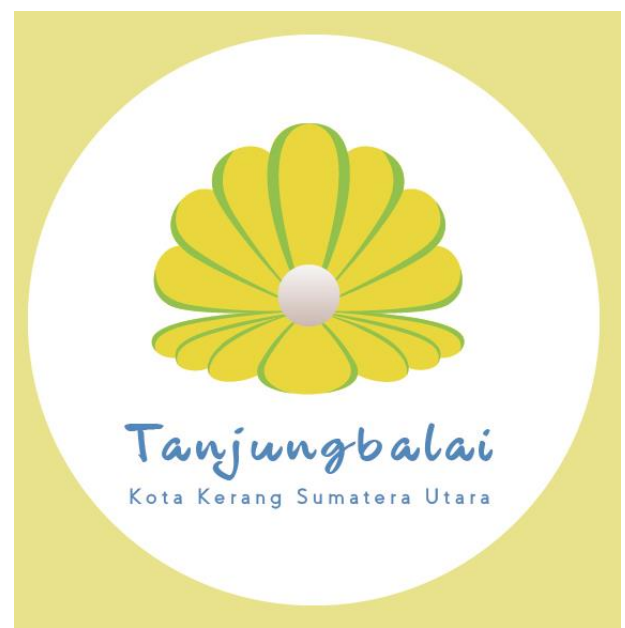

Gambar 17. Desain Sticker

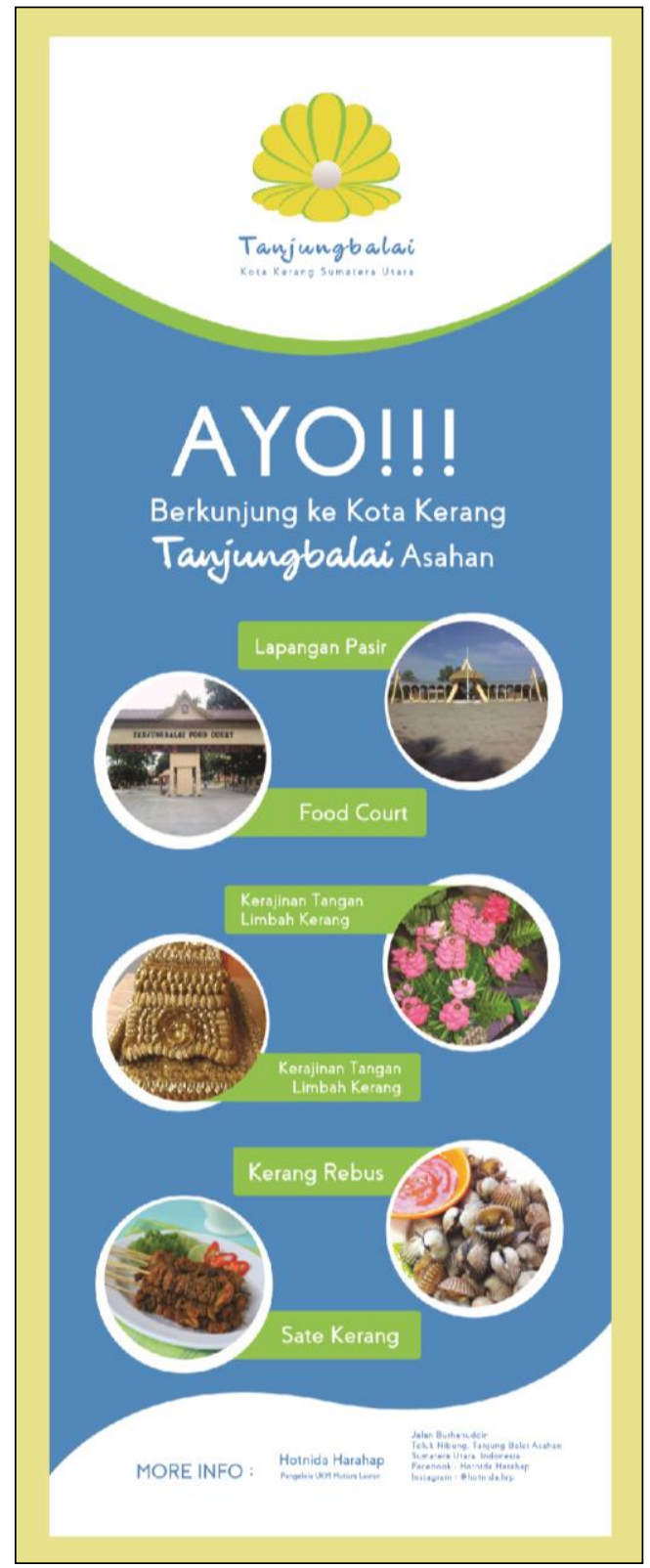

Gambar 18. Desain $X$-Banner 


\section{PENUTUP}

Identitas sangat diperlukan oleh setiap daerah atau kota untuk memperkenalkan daerah atau kota tersebut kepada masyarakat luas. Pengenalan sebuah daerah atau kota dapat ditempuh melalui kata positioning, sloga, icon, lambang, simbol, logo, dan media pendukung yang dianggap efektif dan efisien. Pemilihan media dilakukan berdasarkan data yang ditemukan dan permasalahan yang terdapat pada kota tersebut. Logo Kota Tanjungbalai Asahan merupakan stilasi kerang dara yang terbuka, logo tersebut memiliki pola bentuk yang unik terlihat dari pola garis hijau melengkung yang mengikuti lengkungan setiap shape yang berbentuk seperti cangkang kerang yang terbuka. Garis-garis melengkung ditata sehingga terlihat seperti cangkang kerang. Tageline Kota Tanjungbalai Asahan menjelaskan bahwa kota tersebut berada di provinsi Sumatera Utara yang merupakan daerah penghasil kerang terbesar. Jika tidak menggunakan kata Sumatera Utara pada tagelinenya, maka audient akan bingung dan mengira Kota Tanjungbalai adalah Kota Tanjungbalai Karimun yang berada di Kepulauan Riau.

\section{KEPUSTAKAAN}

\section{Buku :}

[1] Kusrianto, Andi. (2007). Pengantar Desain Komunikasi Visual. Yogyakarta : Andi.

[2] Rhenald, Kasali. (1995). Manajemen Periklanan Konsep dan Aplikasinya di Indonesia. Jakarta : Putaka Utama Grafiti.

[3] Rustan, Surianto. (2010). Mendesain Logo. Jakarta : Gramedia Pustaka Utama.

[4] Rustan, Surianto. (2013). Mendesain Logo. Jakarta: Gramedia Pustaka Utama.

[5] Sanyoyo, Sadjiman Ebdi. (2009). Nirmana Elemen-Elemen Seni dan Desain, Edisi Kedua. Jalasutra: Yogyakarta

[6] Swasty, Wirania. (2016). Branding-Memahami dan Merancang Strategi Merek. Bandung: PT Remaja Rosdakarya.

[7] Weeler, Alina. (2009). Desaigning Brand Identity. Jhon Wiley \& Sons, Inc., Hoboken : New Jersey.

\section{Tulisan/ artikel dalam buku:}

[8] Iskandar, Riki.(2016). Branding Songket Silungkang : Tesis Program Pascasarjana Institut Seni Indonesia : Padangpanjang.

[9] Satria, Haris.(2013). City Branding Kota Padang : Tesis Program Pascasarjana Institut Seni Indonesia : Padangpanjang. 